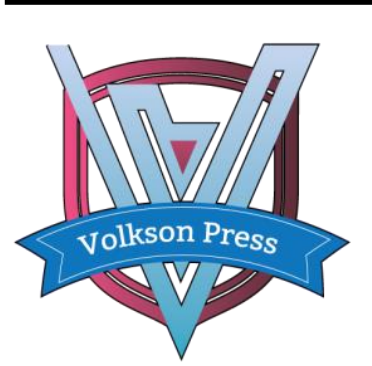

Contents List available at VOLKSON PRESS

Economics \& Management Innovations(EMI)

DOI : http://doi.org/10.26480/icemi.02.2018.13.17

ISBN: 978-1-948012-14-0

\title{
RESEARCH ON THE MOTIVATION, RISK AND COUNTERMEASURE OF HUMAN RESOURCE BUSINESS OUTSOURCING
}

\author{
BI Ke ${ }^{1 *}$, Li Qiuyan², Cao Huan' \\ ${ }^{1}$ School of Economics and Management, Jiangsu University of Science and Technology, Zhenjiang, Jiangsu, China 212003 \\ ${ }^{2}$ School of Foreign Languages, Jiangsu University of Science and Technology, Zhenjiang, Jiangsu, China 212003 \\ *Corresponding Author Email: 835770910@qq.com
}

This is an open access article distributed under the Creative Commons Attribution License, which permits unrestricted use, distribution, and reproduction in any medium, provided the original work is properly cited.

\section{ARTICLE DETAILS}

\section{Article History:}

Received 26 June 2018 Accepted 2 July 2018

Available online 1 August 2018

\begin{abstract}
In recent years, the rapid development of enterprises, especially the rapid development of SMEs, puts forward higher requirements for human resource management, so SMEs can make use of outsourcing to make up their own shortcomings in human resources management, and human resources management content that doesn't involve the core business of the unit can be completed by the external professional outsourcing company, so as to reduce the operating costs and risks and improve the core competitiveness of enterprises, but at the same time there are many non-negligible risk. In this paper, by studding the motivation of human resource management outsourcing in SMEs to analyze the risk of human resource management outsourcing, and ranks the risk level, and then puts forward risk aversion measures, SMEs can better engage to outsourcing activities in a safe and effective manner.
\end{abstract}

\section{KEYWORDS}

Human resource, Management, Outsourcing, risk, Countermeasure.

\section{INTRODUCTION}

In today's increasingly fierce market situation, Survival and sustainable development of enterprises must rely on the strong core competitiveness. In order to let enterprises, have a strong competitive edge, we have planned a set of effective programs of action based on the current situation [1]. However, the benefits of outsourcing process often coexist with the risks. If there is no reliable and comprehensive risk aversion program, it may be "a move by mistake". So, the excellent enterprises strategy that establishes a sound risk prevention measures must ensure it to stand out from the strong market competition [2].

\section{MOTIVATION OF HUMAN RESOURCES OUTSOURCING}

In this context, it refers that the enterprises can outsource the repeated and non-core business to the professional service providers and pays the corresponding service remuneration.

\subsection{The Theoretical Analysis of the Motivation of Human Resources Business Outsourcing}

\subsubsection{Transaction Cost Theory}

The theory of transaction costs was proposed by Coase, the winner of the Nobel Prize in economics) in 1937 and explained the nature of enterprises. The core idea of transaction cost theory is the cost to be paid in the simple process of mutual cooperation that ultimately leads to the transaction under the social contract, in which people are willing to do so [3]. This cost is also the cost to people. It is an important part of human society and always runs through people's exchange activities. Now we will use transaction cost theory to explains the motivation of human resource outsourcing in enterprises.

As can be seen from the transaction process of both parties, the outsourcing of human resources business can not only greatly reduce the labor and material costs, and reduce the transaction costs such as personnel recruitment, personnel training, etc, but also can avoid the case as far as possible that outsourcers use the opportunism to damage the benefit of the enterprises because of information asymmetry.

\subsubsection{Core Competence Theory}

Core competitiveness is rare and outsourcing-based core competencies plays a clever role in making corporate strategies more effective. Enterprise core theory refers that competitive advantage occurs when a organization acquires or develops an attribute or combination of attributes that allows it to outperform its competitors.

It has become a key to achieve competitive advantage whether company can gain a competitive advantage. The core capability is the huge wealth which can be achieved by enterprises in the process of business operation, the gradual accumulation of information resources and human resources and it is the most powerful core element for enterprises to form a competitive advantage.

From the perspective of core competency theory to explain the motivation of human resource outsourcing in enterprises:

In today's rapidly changing market environment, enterprises pay more attention to personnel training and development based on intellectual resources, and the status of human resources management gradually from the original low block, low-tech content into an important part of enterprises to enhance their core competitiveness [4]. According to the theory of core competencies, enterprises only need to handle the contract and communication in order to focus more resources on their own core business for the improvement of internal and excellence, while some noncore business functions are sent to outside "experts" to do. By this way, it will consolidate advantages and market position to continuously improve enterprise core competitiveness while ensuring the strategic efficiency maximization.

\subsubsection{Principal-agent Theory}

The theory of principal - agent mainly researches asymmetric information between clients and agent. The information refers to: If A, B in cooperation, 
A knows the entire contents of the incident $\mathrm{R}, \mathrm{B}$ is unknown-—It is one of the main contractual theory. According to the contract of A and B, A designates $B$ as its work or service, and $B$ has certain decision-making power and management right at work. After the service expires, A pays correspondingly $B$ according to the standard such as the quality, effect and progress of B. In this case, A is the principal, B is the agent.

The motivation of human resources based on the Principal Agent Theory : When outsourcing human resources business as an important strategic choice, the relationship between owner and operator is consignationagency. In the contract between them, the enterprise entrusts the outsource agency to act as human resource business of the company, and the outsourcer has the decision-making and management right over the human resource business in the process of agency. After the contract is completed, the enterprise will pay remuneration according to the quantity and quality of outsourcing work. But until now, the information that company and outsourcer knew was asymmetric, which means enterprise cannot know the actual execution capacity and work level of outsourcer, including the integrity after cooperation. In such a case, outsourcer will take the initiative in information [5]. However, if outsourcing contractors want to achieve stable and long-term cooperation, they must work hard in this situation to win the trust of enterprises, prove their abilities and improve the service level so as to achieve a win-win situation. The enterprises may also continue to maintain cooperation and cooperation with the outsourcers with the deepening of the cooperation through the mode of dividend sharing or shareholding.

\section{HUMAN RESOURCES BUSINESS OUTSOURCING RISK IDENTIFICATION}

\subsection{Human Resource Outsourcing Risk Overview}

Outsourcing risk refers that at the stage of outsourcing, due to the vagaries of the market, the outsourcing service providers' choice, the limited ability to identify the status quo of the enterprise itself and the poor ability of outsourcers to operate, expected goals are may far different, resulting in complete failure of outsourcing strategy and even led to tremendous economic losses.

\subsection{The Main Types of Human Resource Outsourcing Risk}

Table 1: Types of outsourcing risks

\begin{tabular}{|c|c|c|c|}
\hline \multicolumn{2}{|l|}{ Types of risk } & Risk description & $\begin{array}{l}\text { Degree of } \\
\text { risk }\end{array}$ \\
\hline \multirow{3}{*}{$\begin{array}{l}\text { Outsourcing } \\
\text { decision-making } \\
\text { stage }\end{array}$} & legal risk & $\begin{array}{l}\text { Today the law on human resources outsourcing gradually improves } \\
\text { and perfects, but some small and medium-sized enterprises are not } \\
\text { familiar with the relevant laws and regulations such as the } \\
\text { "Enterprise Law," and they often tend to neglect the power of law. } \\
\text { For instance, in 2014, the State Council issued the Opinions on } \\
\text { Promoting the Development of the Service Outsourcing Industry to } \\
\text { make it clear that the Employer shall have the right to institute legal } \\
\text { proceedings against the Employer after the receiving party } \\
\text { compromised the interests of the Employer. }\end{array}$ & $\star \star$ \\
\hline & contract risk & $\begin{array}{l}\text { Enterprise and outsourcing service provider sign a contract between } \\
\text { the formation of a consignation-agent relationship. As the } \\
\text { asymmetric information will make enterprise in a passive position, } \\
\text { outsourcer will may undermine the interest of enterprise, in order to } \\
\text { make his own profits }\end{array}$ & $\star \star \star$ \\
\hline & credit risk & $\begin{array}{l}\text { Low credit service provider may refuse to perform their contractual } \\
\text { obligations and responsibilities, resulting in the breakdown of his } \\
\text { partnership. }\end{array}$ & $\star \star$ \\
\hline $\begin{array}{l}\text { Service provider } \\
\text { selection stage }\end{array}$ & decision risk & $\begin{array}{l}\text { To choose the best match with their own outsourcing service } \\
\text { provider is the key to determine the success of the company's } \\
\text { outsourcing services, otherwise, the company will face serious } \\
\text { economic losses and a decline in the market position. }\end{array}$ & $\star \star \star \star \star ~$ \\
\hline \multirow{2}{*}{$\begin{array}{l}\text { Outsourcing } \\
\text { implementation } \\
\text { stage }\end{array}$} & Control risk & $\begin{array}{l}\text { Outsourcing company and enterprise is a cooperative relationship, } \\
\text { rather than affiliation. They have a certain degree of ability to } \\
\text { operate independently, but if left unmanaged, it will be difficult for } \\
\text { the enterprise to achieve the desired goal. }\end{array}$ & $\star \star \star$ \\
\hline & $\begin{array}{l}\text { Corporate } \\
\text { culture } \\
\text { integration } \\
\text { risk }\end{array}$ & $\begin{array}{l}\text { Differences exist between the culture, concept and values of the } \\
\text { outsourcing company and the enterprise. In daily work, if both } \\
\text { employees misconduct, unnecessary conflicts may occur. }\end{array}$ & $\star \star$ \\
\hline $\begin{array}{l}\text { Outsourcing exit } \\
\text { stage }\end{array}$ & $\begin{array}{l}\text { Trade secret } \\
\text { disclosure } \\
\text { risk }\end{array}$ & $\begin{array}{l}\text { If outsourcing service provider leaks business secrets or core } \\
\text { information to competitors, it will cause unpredictable economic } \\
\text { losses to the enterprise or even a devastating blow. }\end{array}$ & $\star \star \star \star$ \\
\hline
\end{tabular}




\subsection{Root Causes of Human Resource Management Outsourcing Risk}

From the perspective of the main content of outsourcing activities, there are three main causes of human resource management outsourcing risk : enterprises, outsourcers and the external environment. So, it is obvious that the main risks of outsourcing activities also come from these three aspects. The most common source of risk factors of human resources management outsourcing in the market are exactly the same direction. As the table shows:

Table 2: Common source of risk

\begin{tabular}{|c|c|}
\hline \multirow{3}{*}{$\begin{array}{l}\text { Risk factors from the } \\
\text { external environment }\end{array}$} & The development of market environment is not coordinated. \\
\hline & The relevant laws and regulations about outsourcing are not perfect. \\
\hline & The management methods of human resource update fast. \\
\hline \multirow{5}{*}{$\begin{array}{l}\text { Risk factors from } \\
\text { outsourcers }\end{array}$} & $\begin{array}{l}\text { Outsourcers do not know enough about the enterprise and its human resources management } \\
\text { activities. }\end{array}$ \\
\hline & Outsourcers have the opportunistic mind, hidden information and behaviors. \\
\hline & The service quality of outsourcing is expected to be improved. \\
\hline & Excessive workload hampers work process. \\
\hline & The business conditions of outsourcers change. \\
\hline \multirow{11}{*}{$\begin{array}{l}\text { Risk factors from } \\
\text { enterprises }\end{array}$} & Lack of careful analysis the state of human resources management. \\
\hline & Lack of Information for industry market. \\
\hline & Lack of scientific and effective monitoring mechanism. \\
\hline & Outsourcing in pursuit of fashion trends, the purpose is not clear. \\
\hline & Ignore the communication with staff. \\
\hline & Ignore the communication with outsourcers. \\
\hline & Business management is less flexible to adapt to the rapid changes. \\
\hline & Terms of the contract information is not in place. \\
\hline & The fallible judgments that managers are prone to make. \\
\hline & Sign outsourcing contract with haste. \\
\hline & Excessive trust and rely on outsourcers. \\
\hline
\end{tabular}

\section{HUMAN RESOURCE OUTSOURCING RISK PREVENTION}

\subsection{Risk Avoidance in Outsourcing Decision - Making Stage}

Before outsourcing, firstly, enterprise should fully examine the status quo of the enterprise and determine the feasibility of outsourcing decisionmaking. Such as whether the enterprise's limited resources can meet their own core business development, or whether enterprise's long-term management strategy is suitable for outsourcing.

Secondly, in order to prevent the risk of decision-making in signing the contract, the enterprise may employ professional lawyers or professionals who are familiar with the contract law to participate in the negotiation process. At the same time, these personnel should have certain experience on human resources, and not only should carefully check the contract clauses, but also have good negotiating skills, communication skills and analytical skills, the initial judgment of the basic conditions of outsourcing service providers through negotiations. With the above conditions, the contract can be signed smoothly, and the rights and obligations of both parties and other issues of responsibility can be guaranteed.

The signing of the contract is to safeguard the common interests of both parties so as to ensure that the interests of the enterprise are not damaged. The contract should include the specific price of the outsourcing business of both parties, clear definition of the responsibilities and obligations of both parties, the scope of service, the duration of the cooperation, the time of service withdrawal, the way of withdrawal, the agreement of nondisclosure, the expected objectives to be achieved, information security protection and ways of damages (specific amount), work process report and so on. Due to business needs, outsourcers may intentionally or inadvertently disclose corporate secrets, so signing confidentiality in orders to ensure that core secrets are not leaked to third parties or competitors is of particular importance.

\subsection{Risk Aversion for Choice of Outsourcing Service Business}

Choosing the right outsourcing service providers is undoubtedly the key to the successful outsourcing service. If we establish a stable and good cooperation relationship with them, we can not only lower the monitoring cost, but also improve the service level, and ensure the maximum return and achieve a win-win situation. Therefore, the choice of outsourcing is very important and should be cautious. Concrete measures are as follows: (1) It is recommended to consult the precious companies that had cooperation with the sourcing service providers for information, which includes the signing of the contract, the content of the outsourcing, the current implementation, the progress of the work, and the communication channels, because enterprises might be easily misled without no general understanding of the service providers.

(2) Personally "undercover" investigation, that is, enterprises can go to 
their cooperation unit to understand the actual situation, their operational strength, and thus get a clear picture of the situation. At the same time, enterprises should pay attention to the fact that they do not have to choose the best service providers but must choose the outsourcers that are most suitable for the development of their own. Under the premise, we should choose our own partners as follows.

\subsubsection{Establishment of Enterprise Outsourcing Evaluation System}

Generally speaking, Enterprises will be based on the actual situation of their own and set up a suitable and effective performance management system. Its principles include the following:

(1) This evaluation system should objectively reflect the true level of outsourcers, and the system should seek practicality to avoid complexity. (2) The system should be synchronized with the development of the human resources outsourcing industry to adjust and update the system content. In view of the emerging problems in the current industry, the evaluation system should be flexible and timely response.

\subsubsection{Outsourcing Supplier Selection Criteria}

When choosing outsourcing suppliers, enterprises should not just focus on unit price in order to reduce costs, because if enterprises choose a very poor outsourcing agency, the loss will be far greater than this. So, it should be a concrete analysis of concrete problems. In general, enterprises need to pay attention to the following aspects:

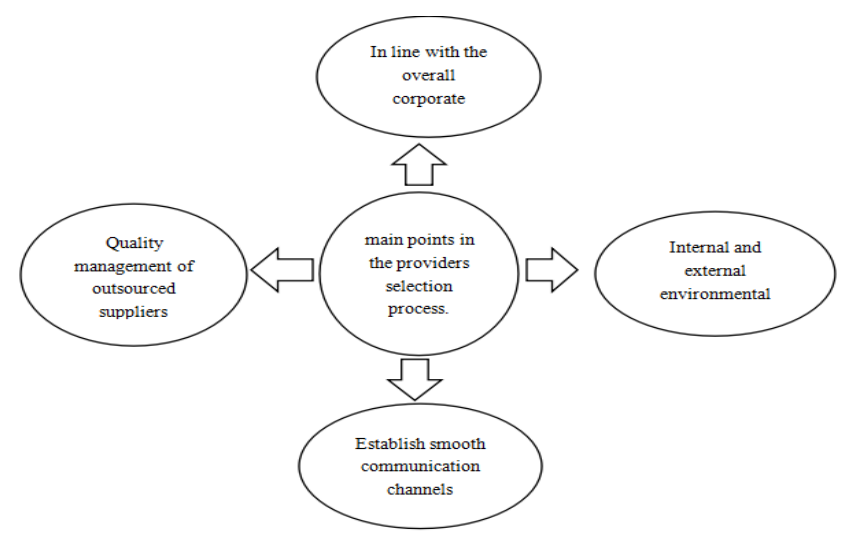

Figure 1: Providers selection points

\subsubsection{Outsourcing Providers Selection Process}

Firstly, it is best to set up outsourcing specialized responsible team. Constituents need to have a full legal awareness and ample understanding of both information, but also have enough loyalty to the enterprise, always the business interests as the most important factor. Secondly, the team should be familiar with internal processes, and risk assessment, good at problem-solving skills and outstanding teamwork and coordination skills.

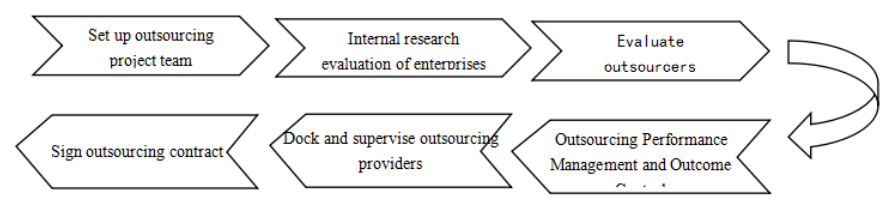

Figure 2: Outsourcer selection process

After the team is established, the enterprise should make a scientific and comprehensive evaluation according to the needs of the suppliers, and at the same time, it should analyze its own internal parts, select the non-core business contents that need to be contracted, and optimize the resource allocation. Second, enterprise should understand specific supervision and filing methods at the various stage. On this basis, enterprises sign a contract with outsourcers. Today, as the rapid development of the world's human resources outsourcing services, many companies even become the world's top 500 enterprises, and choose these businesses has a strong credibility, and execution and information security is guaranteed.

\subsection{Risk Avoidance in Outsourcing Execution Process}

Strengthen supervision. Although outsourcing service providers have some self-care decision-making power and management power in the stage of outsourcing implementation, this does not mean that enterprises can wash their hands of the service providers. In order to avoid the outsourcers deliberately forbid information for personal gain because of the asymmetric information, the enterprises should strengthen supervision and control over outsourcers, enhance mutual communication and timely exchange of information, and understand outsourcing in real time Business dynamics. Take a variety of ways for business interaction. To increase mutual understanding of respective corporate cultures, reinforce recognition of concepts and values of both enterprises, and strengthen cooperation and exchange on the basis of mutual understanding.

Emphasize the use of industry associations to constrain outsourcing service providers. International Association: As an international organization of human resources services, the Private Employment Service Federation can better protect the members' interests. Joining the Association can not only protect their own interests from being infringed but also an intangible asset with a strong brand effect. Domestic Association: China Association of Foreign Service Industries (CAFST), established in 1989, whose service objective is to improve the human resources market system, integrate various advantages of human resources market resources, to maximize their effectiveness and promote development of the industry, strengthening the construction of the association and comprehensively improving the service quality and competitive advantage of the service industry. For example, CIIC (ChinaChile) is the vice president unit of China Association of Foreign Service Industry and AHFESC (Anhui Foreign Service) is the member unit of China Foreign Service Industry Association.

In order to be better managed, industry associations and enterprises in many countries have their own code of conduct that avoids the spread of negative images through self-regulation. For example, the Canadian Human Resources Services Association (ACSESS) was established to ensure ethical standards and good behavior in the industry. The ADP company, referred in the above table also formulated the code of ethics for employees, company management and decision-makers, and even launched the ethics discipline hotline to encourage employees to supervise each other.

\subsection{Risk Avoidance in Outsourcing Aversion Process}

When at the stage of outsourcing, enterprises must pay attention to protect their own core secrets, to remind outsourcers to actively implement the agreement so as to protect their own rights and interests. The 13th Five-Year Plan for the Development of China's International Service Outsourcing Industry and the Opinions on Accelerating the Development of the Service Outsourcing Industry issued by the State Council in 2014 made it clear that if the outsourcer damages the contractor's interests, the Employer is entitled to file legal proceedings. Article 10 of Chapter 5 of the Contract Law: If the recipient fails to comply with the confidentiality agreement with the employer, the employer may bring the arbitration or sue to the competent court according to the agreement of the confidentiality agreement or the service outsourcing contract.

Sub-outsourcing decision-making risk: In the previous round of outsourcing cooperation contract expires, the enterprise is bound to choose a new round of outsourcing services, during which will form a neutral period, the original outsourced business will be re-submitted to the enterprise management. At this point enterprises should properly arrange the transfer of work, so as not to affect the normal work. In this selection of the outsourcer, enterprise should summarize the last experience.

\section{REFERENCES}

[1] Luo, Y. 2007. The Introduction of Service Outsourcing [M]. Xi'an Jiaotong University Press, 11-12. 
[2] Belcourt, M. 2006. Outsourcing-the benefits and the risks [J]. Human Resource Management Review, (16), 1321-1334.

[3] Lever, S. 2007. An analysis of managerial motivations behind outsourcing Practices in Human Resources. Human Resource planning [J], (20), 1343-1357.
[4] Hui, J., Hongyan, M., Sudan, M. 2010. Research on Decision-Making of Enterprise Humen Resource Management Outsourcing [J]. Journal of Jiangsu University of Science and Technology (Social Science Edition), (03), 123-125.

[5] Xiangru, M. 2012. Human Resource Outsourcing Strategies Based on Enterprise Capability [J]. Introduction to Economics, (1), 13-16. 